\title{
BNREL
}
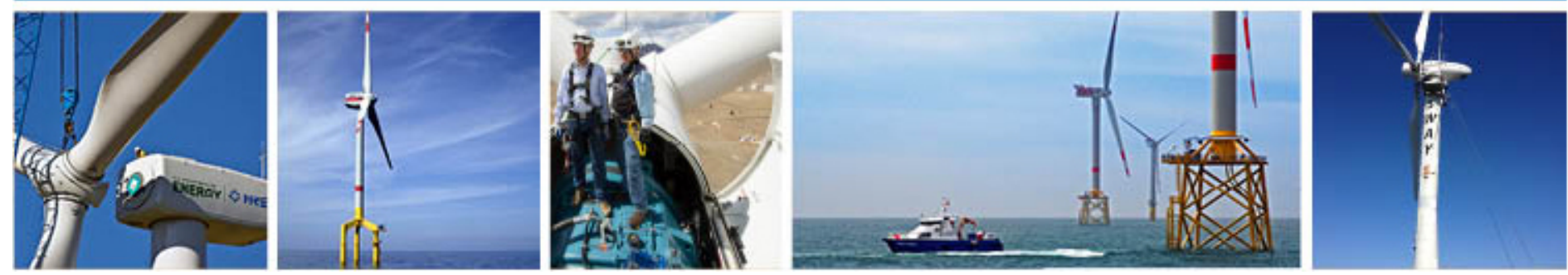

\section{Effects of Second-Order Hydrodynamic Forces on Floating Offshore Wind Turbines}

T. Duarte and A. JNA. Sarmento Instituto Superior Técnico

J. Jonkman

National Renewable Energy Laboratory

Presented at AIAA SciTech 2014

National Harbor, Maryland

January 13-17, 2014

NREL is a national laboratory of the U.S. Department of Energy Office of Energy Efficiency \& Renewable Energy Operated by the Alliance for Sustainable Energy, LLC

This report is available at no cost from the National Renewable Energy Laboratory (NREL) at www.nrel.gov/publications.

\section{Conference Paper}

NREL/CP-5000-60966

April 2014

Contract No. DE-AC36-08G028308 


\section{NOTICE}

The submitted manuscript has been offered by an employee of the Alliance for Sustainable Energy, LLC (Alliance), a contractor of the US Government under Contract No. DE-AC36-08GO28308. Accordingly, the US Government and Alliance retain a nonexclusive royalty-free license to publish or reproduce the published form of this contribution, or allow others to do so, for US Government purposes.

This report was prepared as an account of work sponsored by an agency of the United States government. Neither the United States government nor any agency thereof, nor any of their employees, makes any warranty, express or implied, or assumes any legal liability or responsibility for the accuracy, completeness, or usefulness of any information, apparatus, product, or process disclosed, or represents that its use would not infringe privately owned rights. Reference herein to any specific commercial product, process, or service by trade name, trademark, manufacturer, or otherwise does not necessarily constitute or imply its endorsement, recommendation, or favoring by the United States government or any agency thereof. The views and opinions of authors expressed herein do not necessarily state or reflect those of the United States government or any agency thereof.

This report is available at no cost from the National Renewable Energy Laboratory (NREL) at www.nrel.gov/publications.

Available electronically at http://www.osti.gov/scitech

Available for a processing fee to U.S. Department of Energy and its contractors, in paper, from:

U.S. Department of Energy

Office of Scientific and Technical Information

P.O. Box 62

Oak Ridge, TN 37831-0062

phone: 865.576 .8401

fax: 865.576 .5728

email: mailto:reports@adonis.osti.gov

Available for sale to the public, in paper, from:

U.S. Department of Commerce

National Technical Information Service

5285 Port Royal Road

Springfield, VA 22161

phone: 800.553 .6847

fax: 703.605.6900

email: orders@ntis.fedworld.gov

online ordering: http://www.ntis.gov/help/ordermethods.aspx 


\title{
Effects of Second-Order Hydrodynamic Forces on Floating Offshore Wind Turbines
}

\author{
Tiago M. Duarte* and António JNA. Sarmento ${ }^{\dagger}$ \\ Instituto Superior Técnico, Lisboa, 1049-001 Portugal \\ and \\ Jason Jonkman* \\ National Renewable Energy Laboratory (NREL), Golden, Colorado, 80401
}

\begin{abstract}
Relative to first-order, second-order wave-excitation loads are known to cause significant motions and additional loads in offshore oil and gas platforms. The design of floating offshore wind turbines was partially inherited from the offshore oil and gas industry. Floating offshore wind concepts have been studied with powerful aero-hydro-servo-elastic tools; however, most of the existing work on floating offshore wind turbines has neglected the contribution of second-order wave-excitation loads. As a result, this paper presents a computationally efficient methodology to consider these loads within FAST, a wind turbine computer-aided engineering tool developed by the National Renewable Energy Laboratory. The method implemented was verified against the commercial OrcaFlex tool, with good agreement, and low computational time. A reference floating offshore wind turbine was studied under several wind and wave load conditions, including the effects of second-order slow-drift and sum-frequency loads. Preliminary results revealed that these loads excite the turbine's natural frequencies, namely the surge and pitch natural frequencies.
\end{abstract}

\section{Nomenclature}

$A_{k} \quad=$ complex wave amplitude

$F_{e x}{ }^{(1)} \quad=$ first-order wave-excitation loads

$F_{e x}(2) \quad=$ second-order wave-excitation loads

$X_{i}\left(\omega_{k}\right)=$ first-order excitation transfer function

$X_{i}{ }^{+}\left(\omega_{k}, \omega_{l}\right)=$ sum-frequency quadratic transfer function (QTF)

$X_{i}^{-}\left(\omega_{k}, \omega_{l}\right)=$ difference-frequency quadratic transfer function (QTF)

$\omega_{k} \quad=$ wave frequency

\section{Introduction}

$\mathrm{D}$ EEP water offshore wind has the potential to be an almost endless source of renewable energy. Several floating platforms are currently under development to support wind turbines, based on the knowledge developed in the offshore oil and gas industry. However, floating offshore wind turbines (FOWTs) are not only subject to the same wind loads as land-based turbines, but also current and wave loads. Most of the existing state-of-the-art tools for simulating the coupled aero-hydro-servo-elastic dynamics of FOWTs consider only the first-order wave-excitation loads. However, the second-order wave-excitation forces are known to produce significant slow-drift motions and

\footnotetext{
*Ph.D. Student, MIT Portugal Program, Av. Rovisco Pais 1, 1049-001 Lisboa, Portugal, non-member of AIAA.

${ }^{\dagger}$ Associated Professor, Mechanical Engineering Department, Av. Rovisco Pais 1, 1049-001 Lisboa, Portugal, nonmember of AIAA.

"Senior Engineer, National Wind Technology Center at NREL, 15013 Denver West Parkway, Golden, CO, USA, AIAA Professional Member.
} 
ringing effects in offshore oil and gas platforms. Because little work has been conducted on this subject to date, it is still not clear how these loads affect FOWTs.

The second-order effects, proportional to the square of the wave amplitudes, are derived based on the interaction of a pair of regular waves, with frequencies $\omega_{k}$ and $\omega_{l}$. This interaction generates low-frequency loads with a frequency of $\left|\omega_{k}-\omega_{l}\right|$, known as difference-frequency loads. In the same way, it also creates loads at $\omega_{k}+\omega_{l}$, known as sum-frequency loads. The difference-frequency loads are known to excite the slow-drift motions in slacked moored structures, and are responsible for the mean-drift loads generated by the waves. These loads are particularly important for soft-moored platforms (e.g., catenary), which usually have very high natural periods $(100-150 \mathrm{~s}$ in surge). The sum-frequency loads are typically important for stiffer structures, like fixed-bottom monopole or jacket foundations or tension-leg floating platforms (TLPs), in which they are known to cause ringing effects in these type of structures. For FOWTs, the range of frequencies of the sum-frequency force may also excite the first tower-bending modes.

Figure 1 presents the preliminary results of the first- and second-order wave-excitation loads for the Offshore Code Comparison Collaboration (OC3)-Hywind spar buoy FOWT ${ }^{1}$, under an irregular sea-state modeled by a JONSWAP spectrum, with a significant wave height of $6 \mathrm{~m}$ and a peak-spectral wave period of $10 \mathrm{~s}$. The vertical black lines represent the natural frequency values of the different modes of the floating turbine. As shown in the figure, the second-order loads are often neglected because they have a smaller magnitude than the first-order waveexcitation loads. In addition, the platform natural frequencies tend to be far from the peak of the first-order excitation loads to avoid significant resonance. (The natural frequencies of a FOWT are designed to be either below the wave-excitation frequencies (lower than $0.05 \mathrm{~Hz}$ ) or above the wave-excitation frequencies (above $0.25 \mathrm{~Hz}$ ). In the OC3-Hywind FOWT, the first tower fore-aft and side-to-side bending modes are around $0.45 \mathrm{~Hz}$ and the first blade-bending modes are around $0.65 \mathrm{~Hz}$.) This shows that the difference-frequency loads, while small, may excite the platform motions, while the sum-frequency loads may excite the turbine degrees of freedom (DOFs).

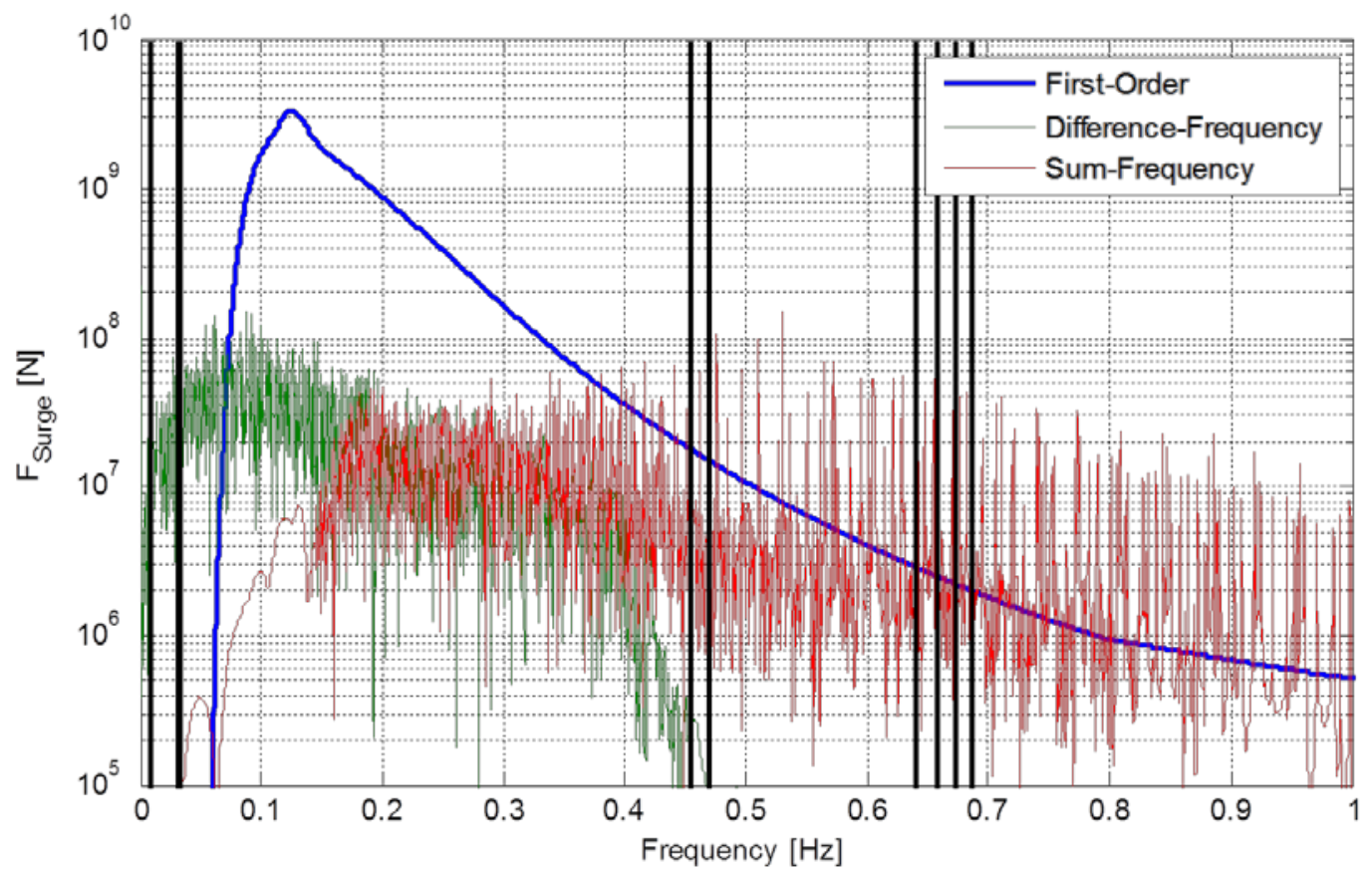

Figure 1. First- and second-order excitation loads and turbine natural frequencies (vertical black lines), for the OC3-Hywind spar buoy under a 6-m, 10-s JONSWAP wave spectrum.

Some studies have already highlighted the importance of second-order loads for FOWTs in low wind conditions. Furthermore, results from scaled wind-wave-tank tests presented in Robertson et al. ${ }^{2}$ indicated the importance of the second-order loads for these types of systems. Significant differences were found between the experimental results and FAST simulations outside the peak wave-energy range with only first-order hydrodynamic loads. The contribution of the low-frequency loads was clearly identified for all three floating platforms tested. Moreover, some differences between the experimental results and the first-order predictions were found for higher frequencies, which indicate the influence of sum-frequency loads, especially for the TLP and tower-base bending loads. Lucas ${ }^{3}$ 
compared the influence of second-order hydrodynamic loads on the OC3-Hywind spar-type floater and on the semisubmersible platform WindFloat. The six rigid-body DOFs of the floating platform were compared for regular and irregular waves, and the comparison showed that the spar is mainly dominated by the first-order component, while the second-order component is important mainly for the surge and pitch DOFs. For the semisubmersible platform, the second-order loads dominated the response, or at least they were on the same order of magnitude as the first-order loads.

This paper presents the methodology used to implement second-order hydrodynamic loads in the time-domain within the wind turbine aero-hydro-servo-elastic tool $\mathrm{FAST}^{4}$. It makes use of quadratic transfer functions (QTFs), which are determined by a frequency-domain panel code (e.g., WAMIT) preprocess step. This method is described in Section II. Section IV includes results from a time-domain analysis for a reference FOWT under load cases presented in Section III.

\section{Calculation of Second-Order Forces}

This section presents the method used to compute the time-domain second-order wave-excitation loads, which are based on the outputs derived with a panel code. WAMIT 6.1S was used to derive the required QTFs for the examples presented in this paper.

\section{A. Time-Domain Implementation}

In order to include the second-order hydrodynamic effects, the second-order loads can be linearly superimposed with the first-order loads. Consider the equation of motion of a rigid platform with six DOFs subject to hydrodynamic loads, as given by the Cummins equation:

$$
\left(M+A_{\infty}\right) \ddot{q}^{t o t}+\int_{0}^{t} K(t-\tau) \dot{q}^{t o t}(\tau) d \tau+C_{\text {hydro }} q^{t o t}=F_{e x}{ }^{(1)}+F_{e x}{ }^{(2)}
$$

where $M$ is the mass matrix of the body, $A_{\infty}$ is the added-mass matrix, $K$ is the retardation matrix, $C_{h y d r o}$ is the hydrostatic stiffness matrix, and $\ddot{q}^{t o t}, \dot{q}^{t o t}$, and $q^{t o t}$ are the body acceleration, velocity, and displacements. The firstand second-order wave-excitation loads are described by the terms $F_{e x}{ }^{(1)}$ and $F_{e x}{ }^{(2)}$. For a single regular incoming wave train, the first-order wave loads are computed using:

$$
F_{e x}{ }^{(1)}{ }_{i}=\operatorname{Re}\left(A X_{i} e^{j \omega t}\right), \quad i=1,2, \ldots, 6
$$

where $A$ represents the complex incoming wave amplitude (characterizing the wave amplitude and phase), $j$ is the imaginary number $\sqrt{-1}$, and $X_{i}$ describes the $i^{\text {th }}$ component of the first-order wave loads per unit amplitude. For long-crested (without directional spreading) irregular sea states, the total load can be seen as a superposition of the different wave-frequency components:

$$
F_{e x}{ }^{(1)}{ }_{i}=\operatorname{Re}\left(\sum_{k=1}^{N} A_{k} X_{i}\left(\omega_{k}\right) e^{j \omega_{k} t}\right), \quad i=1,2, \ldots, 6, \quad \omega_{k}=(k-1) \delta \omega
$$

The normalized first-order wave-excitation force $X_{i}\left(\omega_{k}\right)$ is a function of the platform shape, wave frequency, and wave direction. It is a complex-value vector that accounts for loads out-of-phase with the wave elevation. In FAST, Eq. (3) is implemented via a fast Fourier transform (FFT).

Similar to the first-order excitation, the second-order hydrodynamic load is also frequency dependent. The second-order loads for long-crested (without directional spreading) irregular sea states are divided into the contributions of the sum- and difference-frequencies between pairs of incoming waves. For each pair of incoming waves with amplitude $A_{k}$ and $A_{l}$ and frequencies $\omega_{k}$ and $\omega_{l}$, one can obtain two different QTFs, $X_{i}^{+}\left(\omega_{k}, \omega_{l}\right)$ and $X_{i}{ }^{-}\left(\omega_{k}, \omega_{l}\right)$, corresponding to the $i^{\text {th }}$ component of the sum- and difference-frequency loads. The second-order loads can therefore be obtained using the double Fourier transform:

$$
F_{e x}{ }^{(2)}{ }_{i}=\operatorname{Re}\left(\sum_{k=1}^{N} \sum_{l=1}^{N}\left[A_{k} A_{l} X_{i}^{+}\left(\omega_{k}, \omega_{l}\right) e^{j\left(\omega_{k}+\omega_{l}\right) t}+A_{k} A_{l}{ }^{*} X_{i}^{-}\left(\omega_{k}, \omega_{l}\right) e^{j\left(\omega_{k}-\omega_{l}\right) t}\right]\right), \quad i=1,2, \ldots, 6
$$

where the asterisk $(*)$ denotes the complex conjugate.

1. Symmetry of the QTF Matrices

One should note the following symmetry relations of the QTF matrices:

$$
X_{i}^{+}\left(\omega_{k}, \omega_{l}\right)=X_{i}^{+}\left(\omega_{l}, \omega_{k}\right) \text { and } X_{i}^{-}\left(\omega_{k}, \omega_{l}\right)=X_{i}^{-}\left(\omega_{l}, \omega_{k}\right)^{*}
$$


Taking for now just the difference-frequency term of Eq. (4), one can separate the double summation into three regions: $l=k, l>k$, and $l<k$. In addition, by introducing the variable $\mu^{-}=k-l$, the double summation becomes:

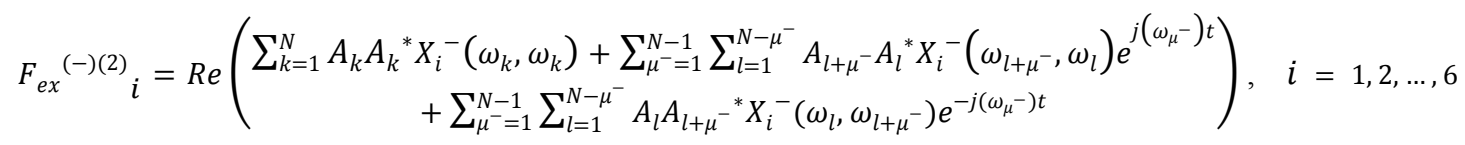

Using the relation in Eq. (5), the last two terms of the previous equation can be grouped and one obtains ${ }^{5}$ :

$$
\begin{gathered}
F_{e x}{ }^{(-)(2)}=\operatorname{Re}\left(\sum_{k=1}^{N} A_{k} A_{k}{ }^{*} X_{i}{ }^{-}\left(\omega_{k}, \omega_{k}\right)+2 \sum_{\mu^{-}=1}^{N-1} H_{\mu^{-}} e^{j\left(\omega_{\mu^{-}}\right) t}\right), \quad i=1,2, \ldots, 6 \\
\text { with } H_{\mu^{-}}=\sum_{l=1}^{N-\mu^{-}} A_{l+\mu^{-}} A_{l}{ }^{*} X_{i}{ }^{-}\left(\omega_{l+\mu^{-}}, \omega_{l}\right), \mu^{-}=1,2, \ldots, N-1
\end{gathered}
$$

The first term in Eq. (7) corresponds to the mean-drift loads and equals the sum of the terms on the diagonal of Figure 2 (a). The second term represents the slow-drift load and corresponds to the sum of the terms with a circle over the blue lines.

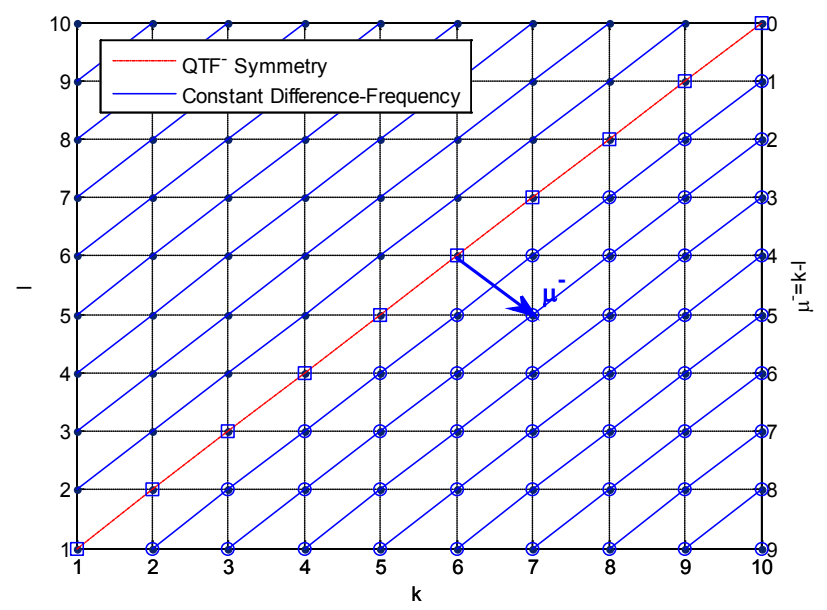

a)

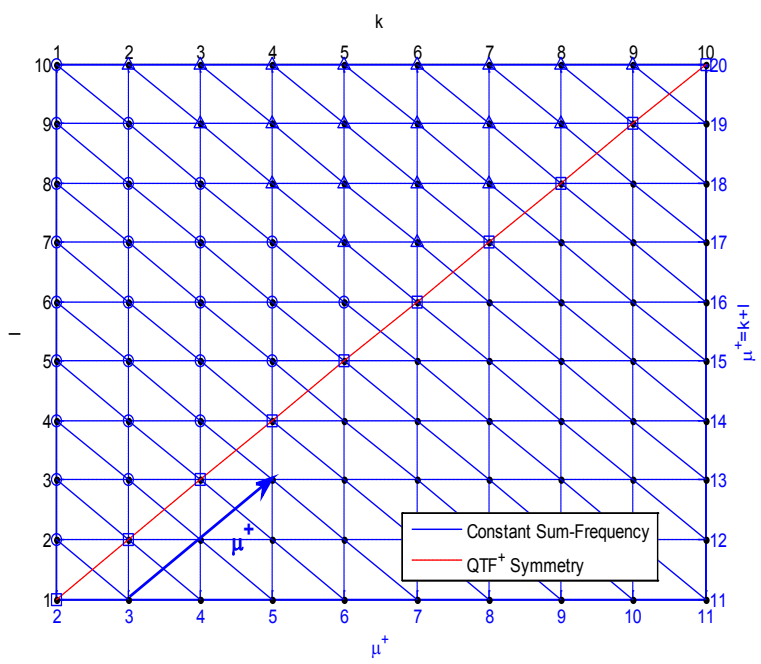

b)

Figure 2. Symmetries of the difference-frequency QTF (left) and sum-frequency QTF (right) matrices, for $N=10$.

Comparing Eq. (6) to the difference-frequency term of Eq. (4), it must be noted that the computational effort is significantly reduced, as one makes use of the symmetry and only takes the lower triangular part of the matrix $X_{i}^{-}\left(\omega_{k}, \omega_{l}\right)$. However, the great advantage of this method is that instead of computing a double inverse Fourier transform (over $\omega_{k}$ and $\omega_{l}$ as in Eq. (4)), it is only required to perform a single inverse Fourier transform over $\omega_{\mu^{-}}$. Therefore, instead of having $N$ inverse Fourier transforms each with $N$ terms, only $N *(N+1) / 2$ sums and a single inverse Fourier transform with $N-1$ terms are employed.

Extending this result to the sum-frequency QTF by introducing the variable $\mu^{+}=k+l$, only a single Fourier transform over $\omega_{\mu^{+}}$can be performed. This corresponds to summing all the terms along each blue line in Figure 2 (b). It should be noted that $0 \leq \omega_{k} \leq \omega_{\max }$, and for the difference-frequency case $0<\omega_{\mu^{-}} \leq \omega_{\max }$, but for the sum-frequency case $0 \leq \omega_{\mu^{+}} \leq 2 \omega_{\max }$. Therefore, we obtain:

$$
F_{e x}^{(+)(2)}{ }_{i}=\operatorname{Re}\left(\sum_{\mu^{+}=2}^{2 N} H_{\mu}+e^{j\left(\omega_{\mu^{+}-1}\right) t}\right), \quad i=1,2, \ldots, 6
$$

$$
\text { with: } \begin{cases}H_{\mu^{+}}=\sum_{l=1}^{\mu^{+}-1} A_{l} A_{\mu^{+}-l} X_{i}^{+}\left(\omega_{l}, \omega_{\mu^{+}-l}\right), & \mu^{+}=2,3, \ldots, N+1 \\ H_{\mu^{+}}=\sum_{l=\mu^{+}-N}^{N} A_{l} A_{\mu^{+}-l} X_{i}^{+}\left(\omega_{l}, \omega_{\mu^{+}-l}\right), & \mu^{+}=N+2, \ldots, 2 N\end{cases}
$$


The approach simplifies the computation of the sum-frequency loads, using only $N^{2}$ sums and a single inverse Fourier transform with $2 N-1$ terms, instead of a double inverse Fourier transform with $N^{2}$ terms in Eq. (4). To make use of the symmetry of the QTF matrix, the matrix should be split into three regions: $l=k, l>k$, and $l<k$. Using the symmetry relations in Eq. (5) we obtain:

$$
\begin{gathered}
F_{e x}^{(+)(2)}{ }_{i}=\operatorname{Re}\left(\sum_{k=1}^{N} A_{k} A_{k} X_{i}^{+}\left(\omega_{k}, \omega_{k}\right) e^{j\left(2 \omega_{k}\right) t}+2 \sum_{\mu^{+}=2}^{2 N} H_{\mu^{+}} e^{j\left(\omega_{\mu^{+}-1}\right) t}\right), \quad i=1,2, \ldots, 6 \\
\text { with: } \begin{cases}H_{\mu^{+}}=\sum_{l=1}^{\left\lfloor\left(\mu^{+}-1\right) / 2\right\rfloor} A_{l} A_{\mu^{+}-l} X_{i}^{+}\left(\omega_{l}, \omega_{\mu^{+}-l}\right), & \mu^{+}=2,3, \ldots, N+1 \\
H_{\mu^{+}}=\sum_{l=\mu^{+}-N}^{\left\lfloor\left(\mu^{+}-1\right) / 2\right\rfloor} A_{l} A_{\mu^{+}-l} X_{i}^{+}\left(\omega_{l}, \omega_{\mu^{+}-l}\right), & \mu^{+}=N+2, \ldots, 2 N\end{cases}
\end{gathered}
$$

where $\lfloor x\rfloor$ represents the floor function of $x$ defined as:

$$
\lfloor x\rfloor=\max \{m \in \mathbb{Z} \mid m \leq x\}
$$

where $\mathbb{Z}$ is the set of integers (positive, negative, and zero). Once again, the first term in Eq. (11) represents the inverse Fourier transform over the terms on the main diagonal of Figure 2 (b). The second term of Eq. (11) represents the inverse Fourier transform over the diagonal blue lines. The first interval of sums in Eq. (12) represents the sum over the round blue dots and the second interval represents the sum over the blue triangles. With this simplification, we further reduce the computational effort to $\left(\left(N^{2}-N\right) / 2\right)$ sums and two inverse Fourier transforms with $N$ and $2 N-1$ terms, respectively.

The total second-order load is therefore the contribution of the following terms:

$$
\begin{gathered}
F_{e x}{ }^{(2)}{ }_{i}=\operatorname{Re}\left(\sum_{k=1}^{N} A_{k} A_{k}{ }^{*} X_{i}{ }^{-}\left(\omega_{k}, \omega_{k}\right)+2 \sum_{\mu^{-}=1}^{N-1} H_{\mu^{-}} e^{j\left(\omega_{\mu}-\right) t}+\sum_{k=1}^{N} A_{k} A_{k} X_{i}{ }^{+}\left(\omega_{k}, \omega_{k}\right) e^{j\left(2 \omega_{k}\right) t}+\right. \\
\left.2 \sum_{\mu^{+}=2}^{2 N} H_{\mu^{+}} e^{j\left(\omega_{\mu^{+}-1}\right) t}\right), \quad i=1,2, \ldots, 6
\end{gathered}
$$

where:

$$
\begin{gathered}
H_{\mu^{-}}=\sum_{l=1}^{N-\mu^{-}} A_{l+\mu^{-}} A_{l}{ }^{*} X_{i}{ }^{-}\left(\omega_{l+\mu^{-}}, \omega_{l}\right), \quad \mu^{-}=1,2, \ldots, N-1 \\
\begin{cases}H_{\mu^{+}}=\sum_{l=1}^{\left\lfloor\left(\mu^{+}-1\right) / 2\right\rfloor} A_{l} A_{\mu^{+}-l} X_{i}^{+}\left(\omega_{l}, \omega_{\mu^{+}-l}\right), & \mu^{+}=2,3, \ldots, N+1 \\
H_{\mu^{+}}=\sum_{l=\mu^{+}-N}^{\left\lfloor\left(\mu^{+}-1\right) / 2\right\rfloor} A_{l} A_{\mu^{+}-l} X_{i}^{+}\left(\omega_{l}, \omega_{\mu^{+}-l}\right), & \mu^{+}=N+2, \ldots, 2 N\end{cases}
\end{gathered}
$$

\section{Mean-Drift Load}

The second-order excitation load includes a mean different from zero, called the mean-drift load (constant term in Eqs. (6) and (14)). This term arises from the quadratic interactions of the first-order problem, and therefore can be computed without requiring the solution of the second-order potential. This can be proven by averaging the solution of the second-order excitation loads. The mean excitation load can be given in terms of a WAMIT-derived transfer function $X_{i}^{\text {Drift }}$ :

$$
F_{\text {ex }}{ }^{(\text {drift })}{ }_{i}=\operatorname{Re}\left(\sum_{k=1}^{N} A_{k} A_{k}{ }^{*} X_{i}^{\text {Drift }}\left(\omega_{k}\right)\right), \quad i=1,2, \ldots, 6
$$

\section{Newman's Approximation}

Because of the computational expense in a frequency-domain panel code of determining the full QTF matrices and the double sum present in Eq. (4), many of the commercial time-domain codes use Newman's approximation [6]. This approach is useful in simplifying the calculation of the slowly varying drift forces, especially for platforms with large natural periods, like the case of moored floating systems. Newman's approximation estimates the offdiagonal terms of the difference-frequency QTF from the diagonal terms. This means that the second-order difference-frequency behavior can be estimated using only the mean-drift QTF derived from the first-order solution.

Using the Newman's approximation, the second-order slow-drift loads are estimated using the following equation ${ }^{6}$ :

$$
\begin{gathered}
F_{e x}{ }^{(-)(2)}{ }_{i}= \\
{\left.\left[\operatorname{Re}\left(\sum_{k=1}^{N} A_{k} \sqrt{2 X_{i}^{-}\left(\omega_{k}, \omega_{k}\right)} e^{j \omega_{k} t}\right)\right]^{2}\right|_{X_{i}^{-}\left(\omega_{k}, \omega_{k}\right)>0}-\left.\left[\operatorname{Re}\left(\sum_{k=1}^{N} A_{k} \sqrt{-2 X_{i}^{-}\left(\omega_{k}, \omega_{k}\right)} e^{j \omega_{k} t}\right)\right]^{2}\right|_{X_{i}{ }^{-}\left(\omega_{k}, \omega_{k}\right)<0},} \\
i=1,2, \ldots, 6
\end{gathered}
$$


Standing et $\mathrm{al}^{7}$ provided a more accurate alternative to this equation, which should be considered in future work. The accuracy of Newman's approximation is better if there is a small variation in the off-diagonal terms when compared with the mean diagonal. On theoretical grounds, the function $X_{i}^{-}$should be continuous in both $\omega_{k}$ and $\omega_{l}$, so the near-diagonal term $X_{i}^{-}\left(\omega_{k}, \omega_{l}\right)$ should be well-approximated by the mean of $X_{i}^{-}\left(\omega_{k}, \omega_{k}\right)$ and $X_{i}^{-}\left(\omega_{l}, \omega_{l}\right)$. Also, the important difference terms are those with low frequency, which arise from the near-diagonal terms in $X_{i}^{-}$. The far-from-diagonal values produce much higher frequencies that have little effect on a platform of sufficiently large inertia. It is also particularly suitable for narrow-banded spectrums, where it can be assumed that the only terms of importance are when $\omega_{k}$ and $\omega_{l}$ are close to each other, therefore the off-diagonal terms can be neglected because of the low magnitude of $A_{k} A_{l}$ for large difference-frequencies.

On the other hand, it should be noted that the Newman approximation can be poor in shallow water, so the full QTF method is preferable in such cases. Additionally, if the vessel is subject to a significant spread of different wave directions, wave pairs with very different directions use far-from-diagonal QTF values but still give low frequency drift-load contributions if their periods are close to each other. So, the full QTF method is also preferable in cases with a spread of wave directions. There is no equivalent approximation for the sum-frequency loads.

\section{B. Verification of the Implementation}

The equations above were implemented in MatLab before being fully incorporated into FAST. The same irregular wave cases were run in both $\mathrm{OrcaFlex}^{8}$ and the developed code. The results were derived using the same QTF matrices for a reference TLP in both codes. The comparison is discussed in the following sections. All of the results refer to a sea state represented by a JONSWAP wave spectrum with a 6-m significant wave height and 10-s peak-spectral wave period. The comparisons shown in this section are aimed only at verifying the implementation and assessment of the equations' computational efficiency.

\section{Mean-Drift Load}

The mean-drift load is constant in time and only depends on the diagonal terms of the difference-frequency QTF matrix. The results of the mean-drift load obtained with the methods presented in Section II. A were compared with the OrcaFlex results. The error between the codes is smaller than $0.2 \%$, which might be caused by the different frequency-domain discretizations.

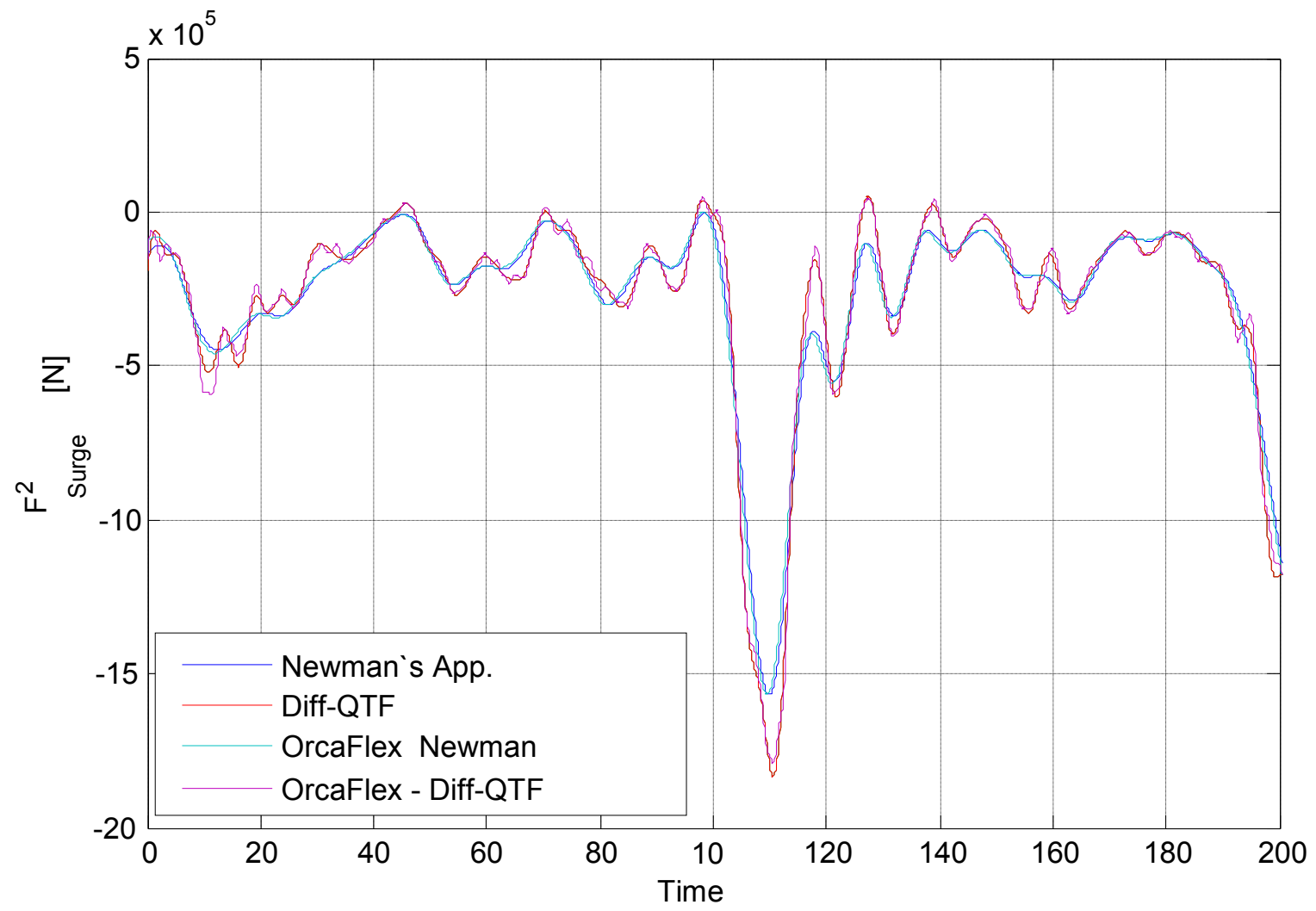

Figure 3. Second-order drift surge force calculated with the Newman's approximation and the full QTF. 


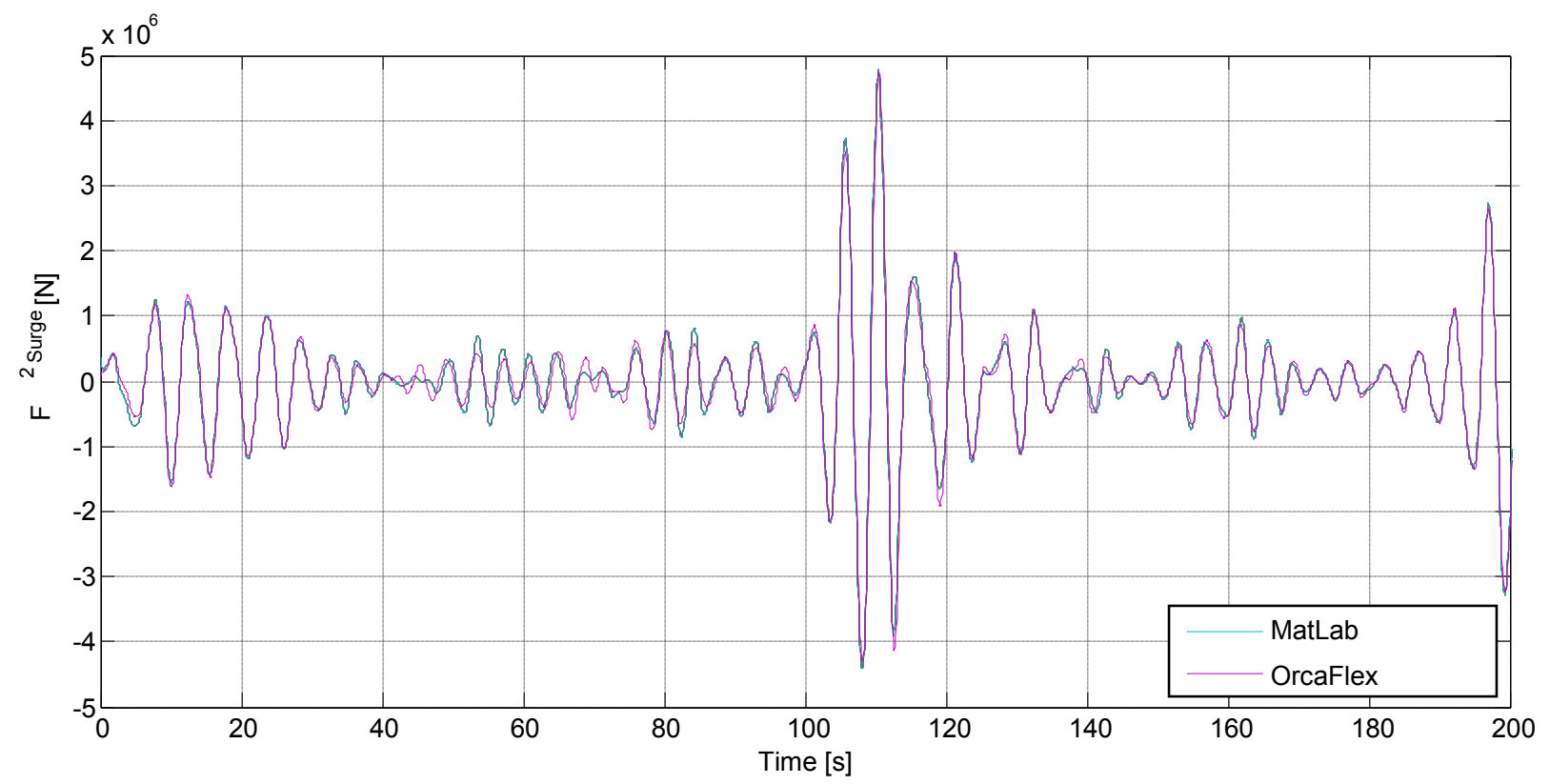

Figure 4. Sum-frequency surge force.

2. Difference-Frequency $Q T F$

The difference-frequency loads were implemented using the single inverse Fourier transform method, described by Eqs. (7) and (8) and made use of a computationally efficient FFT. The JONSWAP wave spectrum was discretized with 40,960 equally spaced frequency steps, while OrcaFlex used 100 discrete frequency steps, spaced with an equal energy discretization. An example of the time-series obtained can be seen in Figure 3.

The agreement for the Newman's approximation method (blue lines) is very good. For the full-QTF method (red and purple lines), some high-frequency content was found in the OrcaFlex signal not present in the implemented code. This occurred because the frequency range considered was limited to 0 to $1.5 \mathrm{rad} / \mathrm{s}$ to save computational time. A sensitivity analysis showed that increasing this range would significantly reduce the differences shown.

3. Sum-Frequency $Q T F$

The sum-frequency loads were implemented using the approach described by Eqs. (11) and (12) and made use of computationally efficient FFTs. To verify the sum-frequency loads, the same approach that was used in the difference-frequency case was applied. The OrcaFlex outputs were compared to the implemented code using the same wave elevation in both codes. An example of the obtained time-series is presented in Figure 4. Overall, the OrcaFlex outputs agreed well with the implemented code. 


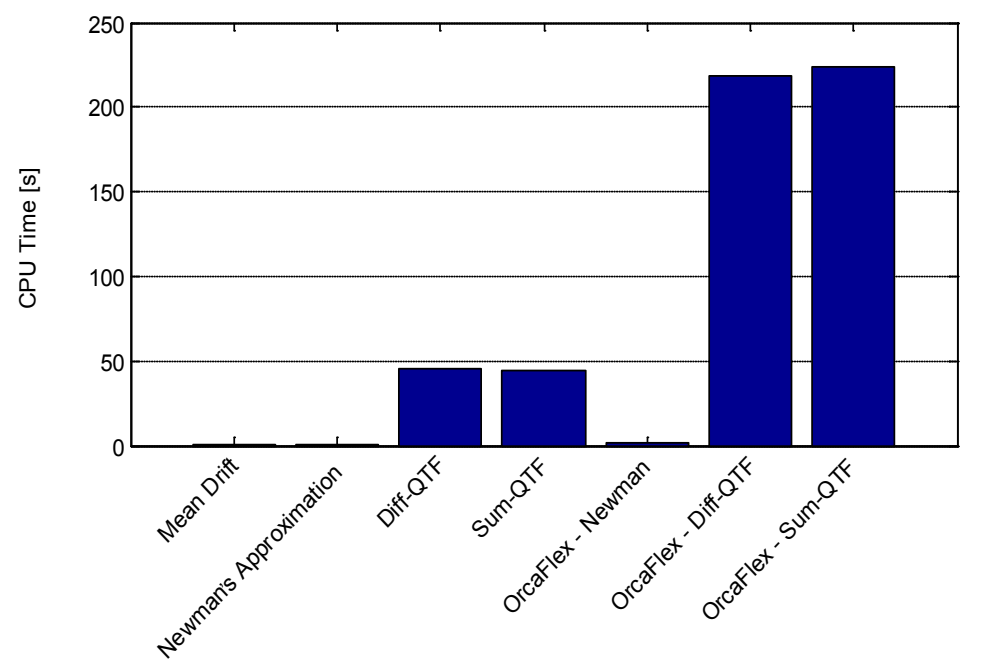

Figure 5. CPU time for the different frequency methods implemented

Figure 5 presents the computational time for the implemented methods. The results were obtained for $4096 \mathrm{~s}$ of the previously described spectrum and were used for computing the loads in the 6 DOF. While the MatLab results used 40,960 equally spaced frequency steps to describe the spectrum, OrcaFlex used a discretized spectrum with the equal energy method (only 100 frequencies). The OrcaFlex model that was created neglected all features except the second-order loads to minimize the additional calculations not performed in the MatLab code and obtain a realistic comparison. These results show the efficiency of the computational method that was implemented, which was enhanced by using the inverse FFT routines. OrcaFlex performs the sum for each discrete frequency, which significantly reduces the number of discrete frequencies used but still requires higher computational times.

\section{Case Study}

This section presents a reference FOWT and the load cases studied in this paper. For the case study, the modeling tool FAST was coupled with the MatLab implementation. As the second-order loads in the time domain depend only on the incoming waves, and not on the motion of the platform, they can be precalculated before running the FAST simulation. The second-order load time-series are precalculated by MatLab, read into FAST, summed with the first-order hydrodynamic loads calculated within FAST, and coupled with the additional aero-servo-elastic features of FAST. The same wave spectrum and time-domain realization was used by both programs.

\section{A. Reference Platform}

The OC3-Hywind spar-type FOWT was chosen for this detailed analysis. The wind-wave-tank tests presented by Robertson et $\mathrm{al}^{2}$ pointed out that this platform might be affected by both difference- and sum-frequency forces. The proprieties of this platform are defined in ${ }^{1}$ and summarized in Figure 6. The difference- and sum-frequency QTFs were derived using WAMIT $6.1 \mathrm{~S}^{9}$. 


\begin{tabular}{|ll|}
\hline \multicolumn{2}{|c|}{ Main Properties of OC3 Hywind } \\
\hline Rated Power & $5 \mathrm{MW}$ \\
\hline Configuration & $\begin{array}{l}\text { Upwind, Three Blades, Variable } \\
\text { Speed }\end{array}$ \\
\hline Rotor Diameter & $126 \mathrm{~m}$ \\
\hline Hub Height & $90 \mathrm{~m}$ \\
\hline Cut-in, Rated, Cut-Out Wind Speed & $3 \mathrm{~m} / \mathrm{s}, 11.4 \mathrm{~m} / \mathrm{s}, 25 \mathrm{~m} / \mathrm{s}$ \\
\hline Platform Draft & $120 \mathrm{~m}$ \\
\hline Platform Diameter Above Taper & $6.5 \mathrm{~m}$ \\
\hline Platform Diameter Below Taper & $9.4 \mathrm{~m}$ \\
\hline Depth to Top of Taper & $4 \mathrm{~m}$ \\
\hline Depth to Bottom of Taper & $12 \mathrm{~m}$ \\
\hline Center of Mass & $(0,0,-78)$ \\
\hline
\end{tabular}

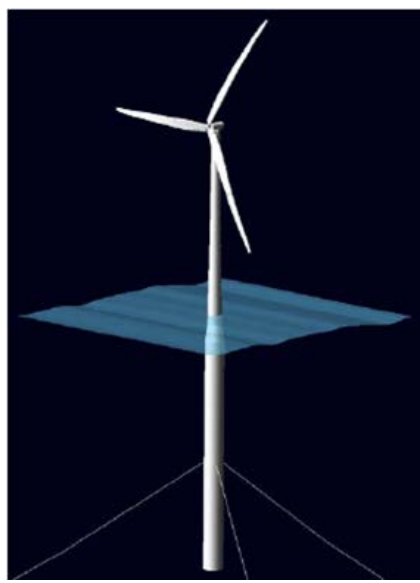

Figure 6. Main properties of the reference OC3-Hywind FOWT.

\section{B. Load Cases}

A partial set of design load cases (DLCs) from those defined in the International Electrotechnical Commission (IEC) 61400-3 offshore wind turbine design standard were used in this work. In order to assess the influence of the second-order loads on the overall system, normal production load cases were selected. Load cases 1.1 and 1.2 were used to assess the ultimate and fatigue loads under normal production. The load case with extreme wave loads (1.6) provides conditions that intensify the second-order effects, resulting in higher extreme loads. (Note that the 50-yr extreme sea state was used for all wind speeds in place of a conditional severe sea state as defined by the IEC for this load case). Finally, load case 2.1 was used to study the platform loads with the turbine parked (the corresponding simulations did not include the transient fault condition). These load cases are summarized in Table 1.

Table 2 summarizes the met-ocean conditions used for a reference site in the North Sea. For more details on the met-ocean data, please consult Jonkman ${ }^{10}$. Each load case was run for wind speed bins of $2 \mathrm{~m} / \mathrm{s}$. For each wind speed bin, six 10-min simulations of $10 \mathrm{~min}$ each were run with different wave seeds and turbulent wind speed fields. The wave height was selected for each wind speed according to the table. For each wind speed, two simulations were run with each peak-spectral wave period value presented in the table, totaling the six simulations per wind speed bin.

Table 1. Design Load Cases.

\begin{tabular}{|c|c|c|c|c|c|c|}
\hline $\begin{array}{l}\text { Turbine } \\
\text { Condition }\end{array}$ & DLC & $\begin{array}{l}\text { Wind } \\
\text { Condition }\end{array}$ & $\begin{array}{l}\text { Wave } \\
\text { Condition }\end{array}$ & $\begin{array}{l}\text { Wind Wave } \\
\text { Directionality }\end{array}$ & $\begin{array}{l}\text { Sea } \\
\text { Current }\end{array}$ & $\begin{array}{l}\text { Type of } \\
\text { Analysis }\end{array}$ \\
\hline \multirow{3}{*}{$\begin{array}{l}\text { Power } \\
\text { Production }\end{array}$} & 1.1 & $\begin{array}{l}\text { NTM } \\
\mathrm{V}_{\text {in }}<\mathrm{V}_{\text {hub }}<\mathrm{V}_{\text {out }}\end{array}$ & $\begin{array}{l}\mathrm{NSS} \\
\mathrm{H}_{\mathrm{s}}=\mathrm{E}\left[\mathrm{H}_{\mathrm{s}} \mid \mathrm{V}_{\mathrm{hub}}\right]\end{array}$ & Aligned & Neglected & Ultimate \\
\hline & 1.2 & $\begin{array}{l}\text { NTM } \\
\mathrm{V}_{\text {in }}<V_{\text {hub }}<V_{\text {out }}\end{array}$ & $\begin{array}{l}\mathrm{NSS} \\
\mathrm{H}_{\mathrm{s}}=\mathrm{E}\left[\mathrm{H}_{\mathrm{s}} \mid \mathrm{V}_{\mathrm{hub}}\right]\end{array}$ & Aligned & Neglected & Fatigue \\
\hline & 1.6 & $\begin{array}{l}\text { NTM } \\
\mathrm{V}_{\text {in }}<V_{\text {hub }}<V_{\text {out }}\end{array}$ & $\begin{array}{l}\text { SSS } \\
\mathrm{H}_{\mathrm{s}}=\mathrm{H}_{\mathrm{s} 50}\end{array}$ & Aligned & Neglected & Ultimate \\
\hline $\begin{array}{l}\text { Parked } \\
\text { Condition }\end{array}$ & 2.1 & $\begin{array}{l}\text { NTM } \\
\mathrm{V}_{\text {in }}<V_{\text {hub }}<V_{\text {out }}\end{array}$ & $\begin{array}{l}\mathrm{NSS} \\
\mathrm{H}_{\mathrm{s}}=\mathrm{E}\left[\mathrm{Hs} \mid \mathrm{V}_{\mathrm{hub}}\right]\end{array}$ & Aligned & Neglected & Ultimate \\
\hline $\begin{array}{l}\text { NTM: Norm } \\
\text { NSS: Norma } \\
\text { SSS: Severe }\end{array}$ & $\begin{array}{l}\text { Turbu } \\
\text { eea Sta } \\
\text { a State }\end{array}$ & $\begin{array}{ll}\text { del } & \mathrm{V}_{\text {in }}: \mathrm{Cu} \\
& \mathrm{V}_{\text {hub }}: \mathrm{H} \\
& \mathrm{V}_{\text {out }}: \mathrm{Cl}\end{array}$ & $\begin{array}{l}\text { In Wind Speed } \\
\text {-Height Wind S } \\
\text {-Out Wind Speec }\end{array}$ & eed & $\begin{array}{l}\text { ignificant V } \\
\text { eak-Spectra }\end{array}$ & $\begin{array}{l}\text { Height } \\
\text { ve Period }\end{array}$ \\
\hline
\end{tabular}


Table 2. Met-Ocean Conditions.

\begin{tabular}{ccccc} 
Wind Speed $(\mathrm{m} / \mathrm{s})$ & Significant Wave Height $(\mathrm{m})$ & \multicolumn{3}{c}{ Peak-Spectral Wave Period(s) } \\
\hline 4 & $1.586(\mathrm{NSS})$ & 8,97 & 12,67 & 16,43 \\
6 & 1.758 (NSS) & 7,98 & 12,67 & 17,37 \\
8 & 1.837 (NSS) & 7,98 & 12,67 & 17,37 \\
10 & 2.194 (NSS) & 9,15 & 13,38 & 17,60 \\
12 & $2.402(\mathrm{NSS})$ & 9,15 & 13,38 & 17,60 \\
14 & 2.988 (NSS) & 8,68 & 11,97 & 15,25 \\
16 & 3.373 (NSS) & 10,09 & 13,38 & 16,66 \\
18 & 3.673 (NSS) & 10,09 & 13,38 & 16,66 \\
20 & 4.441 (NSS) & 11,26 & 14,08 & 16,90 \\
22 & 4.720 (NSS) & 11,03 & 13,38 & 15,72 \\
24 & 5.521 (NSS) & 12,67 & 15,49 & 18,30 \\
Any & 15.04 (SSS) & & 19.22 & \\
\hline
\end{tabular}

\section{Results}

This section presents the results from the analysis of the OC3-Hywind FOWT. Spectral analysis results of the different load cases are presented in the next subsection, followed by the ultimate loads and fatigue results. Each load case was run without second-order loads, and with Newman's approximation, difference-frequency full QTF, sum-frequency full QTF, and both difference- and sum-frequency QTFs together (the complete second-order solution). Platform surge and pitch motion, fairlead tension of one of the upwind mooring lines, and tower-base bending moments are also analyzed in the following sections.

\section{A. Spectral Analysis}

\section{No Wind Loads}

Figure 7 shows the power spectral results with and without second-order loads for conditions without wind. These results correspond to the IEC load case 2.1 after the fault-induced shutdown. For this analysis, a JONSWAP spectrum with 3-m significant wave height and an 8-s peak-spectral wave period was chosen. The influence of the second-order loads is clearly visible for frequencies below the wave range, as predicted by Lucas ${ }^{3}$. In most of the figures, the results with the difference-frequency QTF (red line) are below the results of the complete second-order solution (purple line). The first-order results (dark blue line) are below the sum-frequency results, especially below the wave region, where the sum-frequency loads are negligible.

The surge power spectral density shows a significant increase in surge motion below the first-order wave range, especially around the pitch and surge natural frequencies $(0.035 \mathrm{~Hz}$ and $0.01 \mathrm{~Hz}$, respectively). There is a significant increase of the pitch motion caused by the difference-frequency load, which is largely neglected when using Newman's approximation. The fairlead mooring tension shows a similar behavior, with an increase around the pitch natural frequency $(0.3 \mathrm{~Hz})$. It should be noted that by using the quasi-static mooring module of FAST, we are neglecting the mooring line dynamics that would contribute to an increased response for the sum-frequency range. Finally, the tower-base moment shows an increase around the pitch natural frequency caused by the differencefrequency loads. No significant effect related to the sum-frequency loads was observed. This result is most likely because the large platform inertia is acting as a filter to these higher frequency loads. 

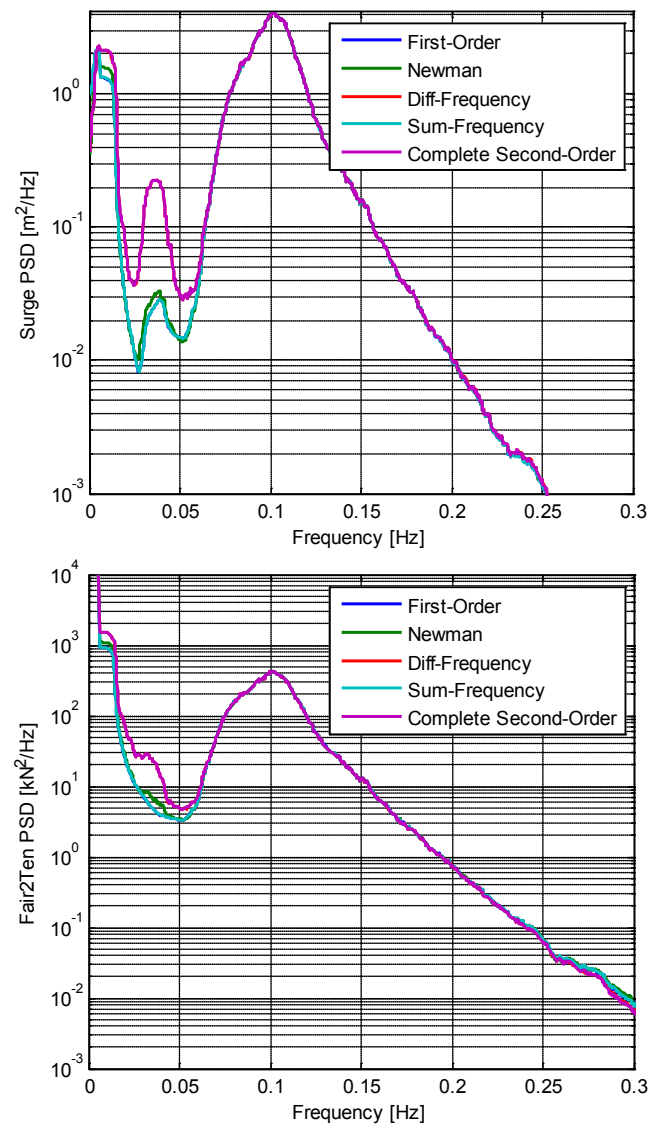
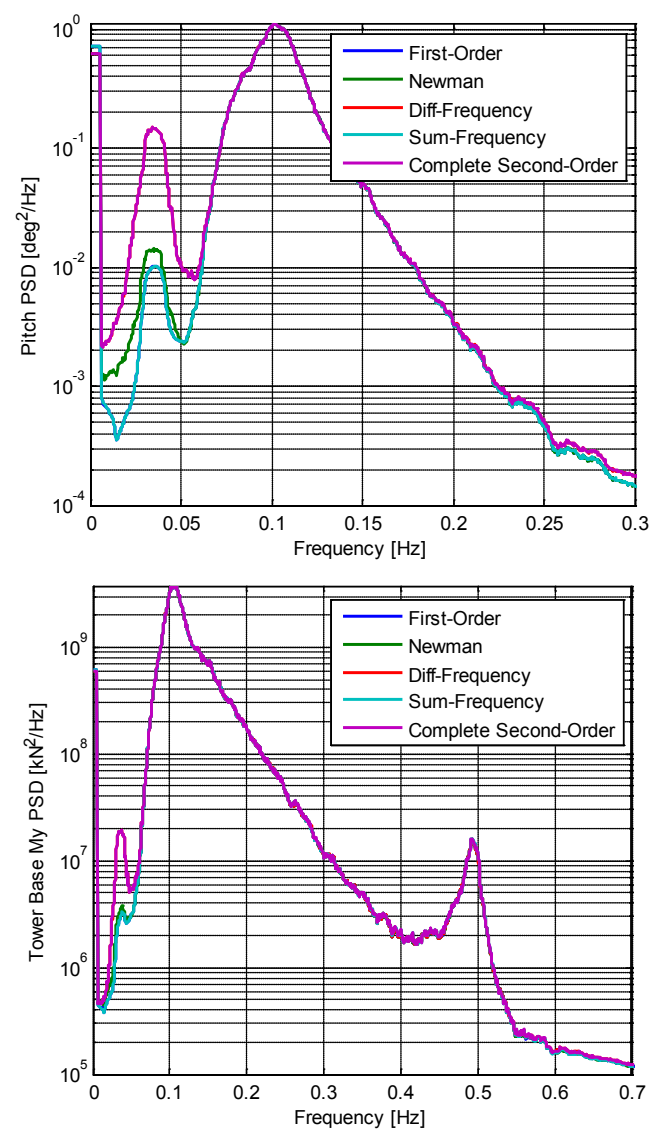

Figure 7. Power spectral results obtained without wind loads. Top left: surge motion; top right: pitch motion; lower left: fairlead tension; lower right: tower-base moment.

\section{Normal Sea State with Wind Loads}

The operating turbine generates a significant thrust force acting on the tower top, forcing the turbine to drift from its equilibrium position. This force is usually significantly higher than the mean-drift surge force caused by secondorder wave loads. Figure 8 presents the power spectral density of the platform motion and loads under the operating load case $(1.1 / 1.2)$. The surge motion is now dominated by the wind thrust force, and no significant differences can be found for the case including second-order loads. However, the influence of the difference-frequency loads around the platform-pitch natural frequency is still visible in the pitch motion. Once again, Newman's approximation underestimates the second-order excitation for this region, when compared to the full QTF approach.

The loads acting on the mooring line follow the surge-motion results. No significant differences were found between the cases, as the wind loads were driving the surge motion and consequently the mooring line tension. For the tower-base bending moment, some additional loads were found around the pitch natural frequency of the spar buoy.

\section{Extreme Wave Load Case}

Load case 1.6 is dominated by an extreme sea state of 15.69 -m significant wave height and 19.22-s peak-spectral wave period (see Figure 9). Despite the wind load acting on the rotor, the influence of the second-order loads is now visible for the platform surge motion, especially around the pitch natural frequency. This effect is also visible on the pitch motion, where once again Newman's approximation tends to underestimate this effect. This difference also occurs for the mooring line tension and tower-base moments. Because of the larger periods, the sum-frequency loads now have a visible influence on the tower-base moment (although still very small), around the first tower-bending natural frequency. 

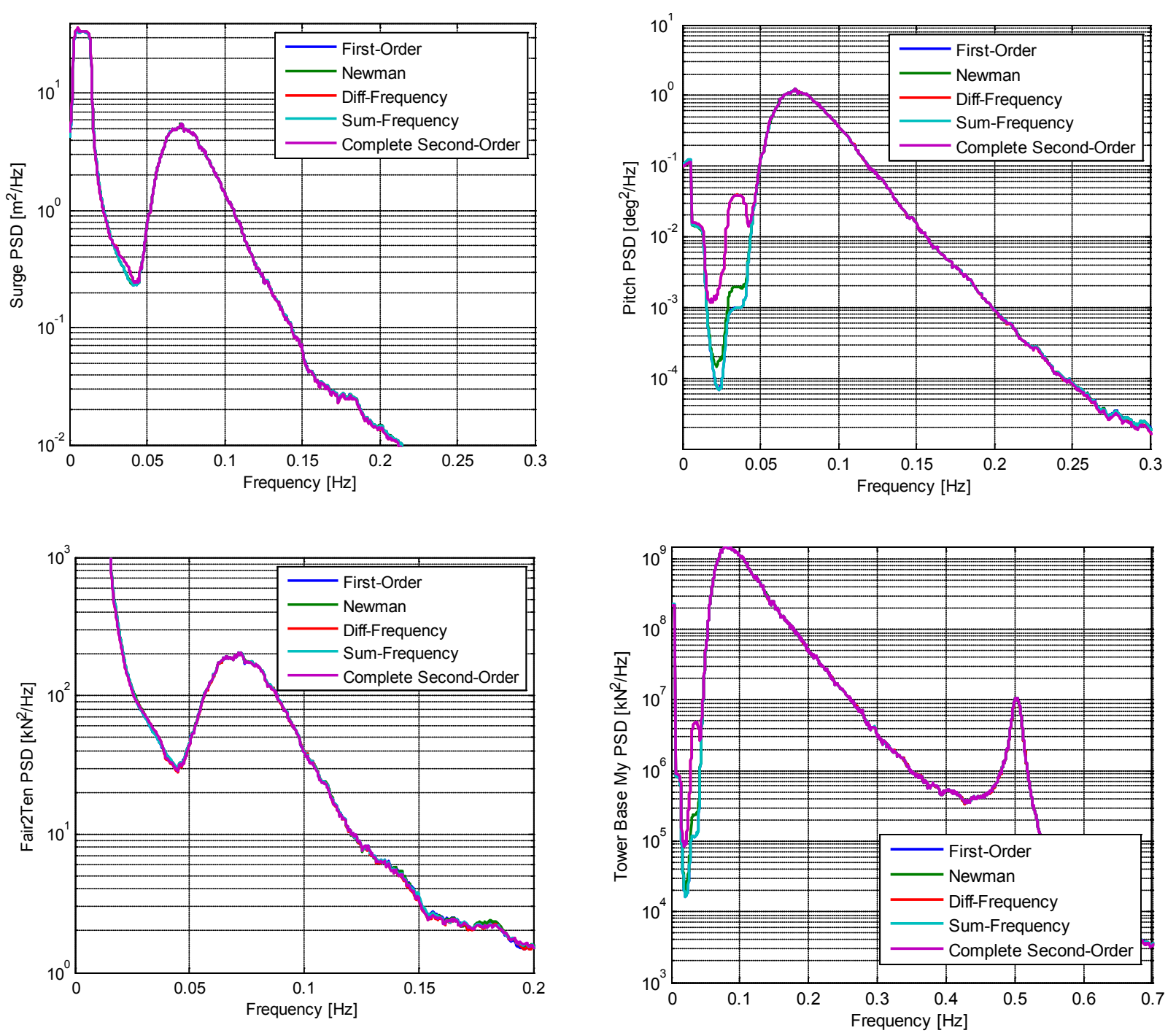

Figure 8. Power spectral results obtained for IEC load case 1.1 and 1.2. Top left: surge motion; top right: pitch motion; lower left: fairlead tension; lower right: tower-base moment. 

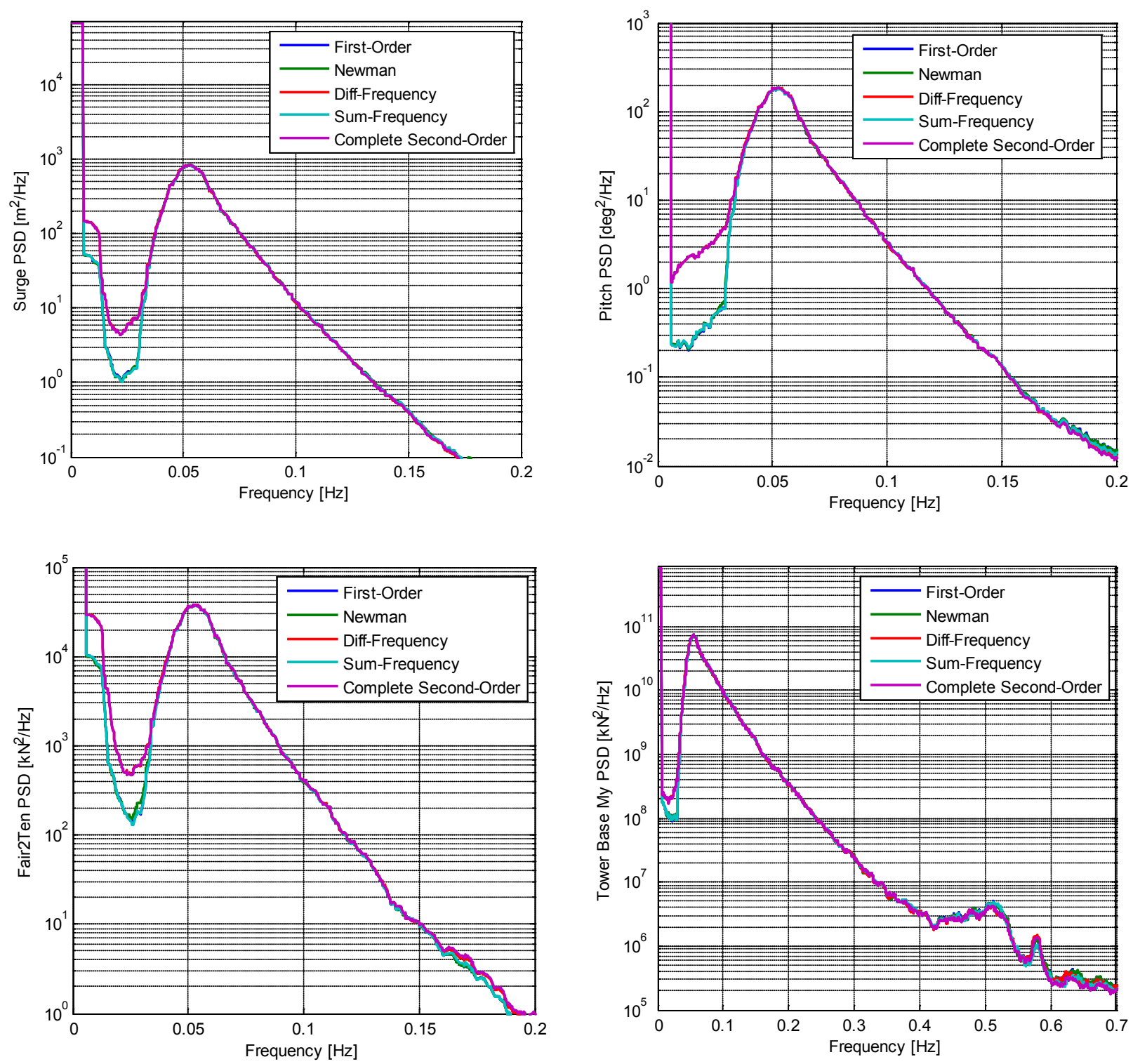

Figure 9. Power spectral results obtained for IEC load case 1.6. Top left: surge motion; top right: pitch motion; lower left: fairlead tension; lower right: tower-base moment.

\section{B. Ultimate Loads}

Figure 10 presents the ultimate loads found for the different load cases studied. No partial load factors were included in the results. The difference-frequency loads caused the biggest increase in maximum surge displacement (under the extreme wave conditions). However, no significant changes were observed in the maximum fairlead tension. As for the surge motion, IEC load case 1.6 caused the highest differences in the extreme platform-pitch motion. The same result occured for the ultimate tower-base bending moment, in which the case including the sumfrequency loads showed the highest moment. 

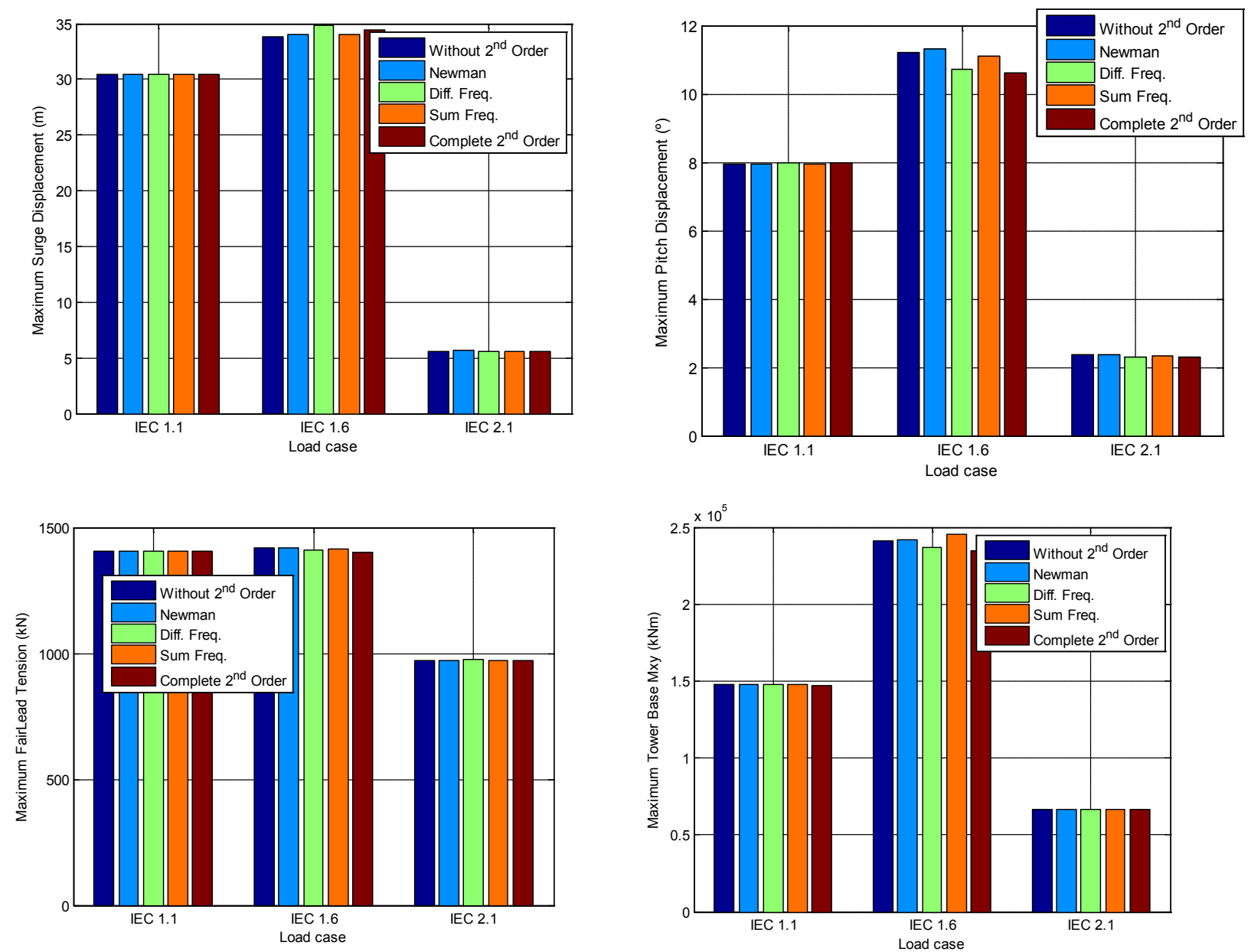

Figure 10. Ultimate loads for the different load cases studied. Top left: surge motion; top right: pitch motion; lower left: fairlead tension; lower right: tower-base moment.

\section{Fatigue Analysis}

Fatigue analysis was performed for load case 1.2. using MLife ${ }^{11}$. The lifetime damage results were normalized by the case without second-order loads. A value higher than one indicates an increase in the lifetime damage, as presented in Figure 11. Very small changes were found between the fatigue life predictions with and without second-order loads. The biggest changes occured for the tower-base bending moment with the full differencefrequency QTF. However, these changes still represent less than a $1 \%$ increase in fatigue life. One possible reason for the lack of difference is the length of the simulation. According to the IEC, each load case for fixed-bottom offshore wind turbines should be run for 10 minutes with different random seeds. However, this simulation length seems to be too short to capture the effects of the slow-drift motion of FOWTs, especially in platforms with very large surge/sway natural frequencies. An investigation of the sensitivity to the simulation length should be performed in a follow-up study. 


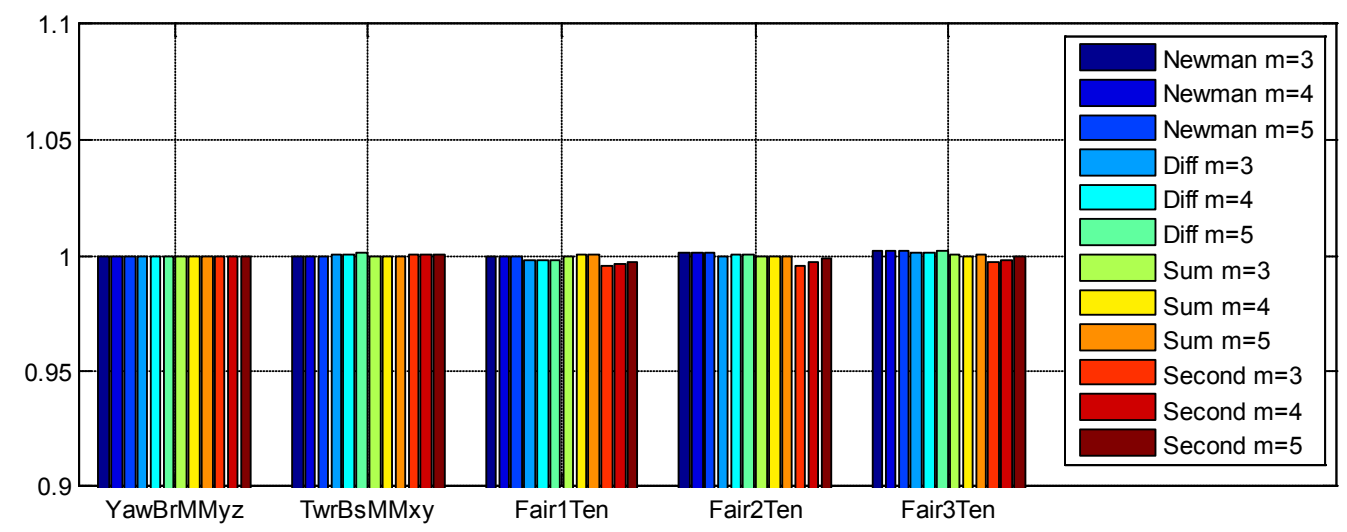

Figure 11. Fatigue life damage normalized by the case without second-order effects.

\section{Conclusions and Future Work}

A computationally efficient method to determine the second-order wave loads on FOWT in the time-domain was presented in this paper. The method was implemented in MatLab and verified against the commercial code OrcaFlex. The results indicated very good agreement with significant time savings.

A preliminary analysis of the influence of these second-order wave loads on the OC3-Hywind floating spar-type wind turbine was also performed. The spectral analysis revealed a significant increase of the surge and pitch motion of the floating platform below the first-order wave-frequency region. Significant differences were found between Newman's approximation and the full QTF method, especially close to the pitch natural frequency, but no significant contribution was found from the sum-frequency loads. The effects of second-order wave loads were significantly reduced for the load cases with the active turbine because of the dominance of wind loads. The ultimate load analysis revealed minor influences of the difference-frequency loads, which occurred particularly for the extreme wave load case. The fatigue analysis did not show any significant effect from the second-order wave loads.

The MatLab routine will soon be converted to Fortran and implemented directly within FAST, which will enable further analysis of FOWTs with second-order hydrodynamic loads. The spreading of the sea state across different wave directions (not discussed in this paper) is also being considered in this implementation. The simulation length used in this analysis should be revisited in a future study, as evidence has shown that 10-min simulations are not long enough to fully resolve the effects of the slow-drift second-order loads. Also, the importance of second-order wave loads on other floating platforms will be assessed; second-order loads are likely to be more important in semisubmersibles and TLPs.

\section{References}

1 J. Jonkman, "Definition of the Floating System for Phase IV of OC3," NREL, Golden, Colorado, 2010.

2 A. N. Robertson, J. M. Jonkman, A. J. Groupee, A. J. Coulling, I. Prowell, J. Browning, M. Masciola and P. Molta, "Summary of Conclusions and Recomendations drawn from the DeepCWind scaled floating offshore wind system test campaign," in Proceedings of the ASME 2013 32nd International Conference on Ocean, Offshore and Arctic Engineering, Nantes, France, 2013.

3 J. Lucas, "UpWind Project: Comparison of First and Second-Order Hydrodynamic Results for Floating Offshore Wind Structures," Garrad Hassan \& Partners Ltd., Bristol, UK, 2011.

4 NREL, "NWTC Computer-Aided Engineering Tools (FAST by Jason Jonkman, Ph.D.).," 0211 2012. [Online]. Available: http://wind.nrel.gov/designcodes/simulators/fast/. [Accessed 1211 2012].

5 R. S. Langley, "On the time domain simulation of second order wave forces and induced responses," Applied Ocean Research, vol. 8, no. 3, 1986.

6 J. N. Newman, "Second-order, Slowly-varying Forces on Vessels in Irregular Waves," in Proceedings of International Symposium on Dynamics of Marine Vehicles and Structures in Waves., London, 1974. 
7 R. G. Standing, W. J. Brending and D. Wilson, "Recent Developments in the Analysis of Wave Drift Forces, Low-Frequency Damping and Response," in Proceedings of the 79th Annual OTC, Houston, Texas, 1987.

8 Orcina, "OrcaFlex Manual - Version 9.6," 2012.

9 L. A. Roald, "The Effect of Second-Order Hydrodynamics on a Floating Offshore Wind Turbine," Eidgenössische Technische Hochschule Zürich-Master Thesis, Zürich, 2012.

${ }^{10}$ J. Jonkman, "Dynamic Modeling and Loads Analysis of an Offshore Floating Wind Turbine," NREL, Golden, Colorado, 2007.

${ }^{11}$ NWTC, "NWTC Design Codes (MLife by Greg Hayman)," 2012. [Online]. Available: http://wind.nrel.gov/designcodes/postprocessors/MLife/. [Accessed 2013]. 